\title{
BALLOTAGE VERSUS COLEGIO ELECTORAL. SISTEMAS ELECTORALES Y ELECCIONES PRESIDENCIALES EN ARGENTINA*
}

\author{
Ernesto Cabrera**
}

Este artículo se centrará en algunas características institucionales de los sistemas electorales del pasado y del presente en Argentina y en la problemática relación entre estas características y las tendencias de cambios que el sistema de partidos ha estado experimentando desde 1983. Después de diez años de gobierno democrático legalmente basado en la Constitución Nacional de 1853, Argentïna atravesó por un complejo proceso de reforma constitucional. Entre otros importantes cambios, la nueva Constitución (aprobada en 1994) reformó las reglas para la elección presidencial: se abolió el viejo sistema indirecto de colegios electorales, copiado de la Constitución norteamericana y estableció un nuevo sistema de elección nacional directa (1).

Este artículo tiene dos objetivos: a) demostrar que hay una tendencia hacia el incremento de la fragmentación del sistema de partidos argentino; y b) mostrar que, más allá de la negociación de beneficios particulares para los dos principales partidos (peronistas y radicales), era necesario abolir el sistema del Colegio Electoral porque se estaba volviendo una amenaza para la estabilidad institucional.

En otras palabras, a) el mantenimiento de tres sistemas multipartidistas provinciales, junto con el lento declinar de los dos principales partidos tradicionales en los mayores distritos y una explosión de partidos conservadores locales en las provincias medianas, está cambiando lentamente el sistema de partidos nacional; y b) la combinación del Colegio Electoral con el principio mayoritario, la representación proporcional para asignar a los electores presidenciales, una mala delimitación entre distritos y esta tendencia hacia un sistema multipartidista, estaba poniendo la estabilidad y continuidad del régimen democrático en Argentina en riesgo.

Después de la derrota de la guerra de las Malvinas en 1982, el régimen militar que había comenzado con el

(*) Traducción de Fernando Harto de Vega y Ana Inés López-Accotto. (**) Universidad de Pittsburgh.

(1) La fórmula electoral usada en esta elección no es ni mayoritaria ni proporcional. El ganador llega a ser presidente si (i) él o ella obtiene más del 45 por ciento de los votos o (ii) él o ella obtiene más del 40 por ciento de los votos y este porcentaje es, al menos, superior en diez puntos al porcentaje del segundo candidato. De lo contrario, debe tener lugar una segunda vuelta entre los dos candidatos más votados. golpe de 1976 fue completamente deslegitimado y comenzó una rápida retirada que condujo al establecimiento de un nuevo régimen político mediante elecciones libres en 1983. Las elecciones legislativas se han celebrado con continuidad en 1985, 1987, 1989, 1991, 1993 у 1995. Las elecciones presidenciales tuvieron lugar en 1983, 1989 y en 1995.

La derrota del partido peronista en 1983, por primera vez en elecciones libres, marcó el fin de una era de hegemonía política de un partido dominante y el comienzo de un período de verdadera competición electoral e incertidumbre en los resultados. Desde 1916 a 1943, la Unión Cívica Radical fue el partido dominante y el ganador indiscutido de todas las elecciones nacionales libres. Desde 1945 a 1975 , el partido peronista fue el partido dominante y el seguro ganador de las elecciones nacionales. Las intervenciones militares (desde el derrocamiento del gobierno de Perón en 1955) fueron intentos de detener el retorno político del peronismo al poder a través de elecciones.

Sin embargo, el triunfo electoral del candidato presidencial radical, Raúl Alfonsín, que obtuvo la mayoría del voto popular en 1983, fue un punto de inflexión en la política argentina y un golpe para la tradicional imbatibilidad del peronismo. Fue la primera derrota nacional del peronismo en elecciones limpias. Significa el fin de la imagen de una mayoría peronista eterna y el comienzo de una reorganización interna democrática para el partido peronista.

En 1987, las elecciones para gobernador en las provincias produjeron el primer recambio democrático de gobernadores desde 1962. En 1989, el candidato presidencial Carlos Menem, ganó las elecciones produciéndose el primer traspaso democrático de poder entre partidos para la presidencia desde 1916. Estos dos hechos subrayan la importancia del comienzo de una competición electoral verdadera en el caso argentino.

Algunos autores han interpretado los resultados electorales de los años que transcurren entre 1983 y 1993 como la emergencia de un nuevo sistema bipartidista. A pesar del continuado dominio histórico de los principales partidos en las elecciones nacionales, sostengo que hay un proceso continuo de debilitamiento de los dos partidos tradicionales 
(peronistas y radicales) cuyo ritmo difiere, por un lado, en los niveles de análisis nacionales y provinciales; y, por otro, en las elecciones legislativas y para los cargos ejecutivos (para presidente y gobernadores) (2).

Las elecciones en Argentina han mostrado un lento pero sostenido proceso de pluralización. Desde 1983, cuando Argentina retornó a la forma constitucional de gobierno, ha habido un continuo decrecer en la concentración de votos alrededor de los partidos radical y peronista y una ligera pero sostenida tendencia hacia el multipartidismo (3).

Este proceso gradual de desconcentración de los votos desde el radicalismo/peronismo hacia los partidos minoritarios o provinciales llegó a ser un fenómeno extremadamente importante cuando las elecciones nacionales fueron analizadas y los resultados fueron desagregados por provincias. Esto fue así porque las elecciones presidenciales en Argentina son indirectamente dilucidadas a través de los resultados en el nivel de los distritos provinciales.

Como en los Estados Unidos, la antigua Constitución nacional argentina (1853) estipuló un sistema de Colegio Electoral para elegir al presidente. Los electores presidenciales son distribuidos de acuerdo con los resultados en cada distrito. En otras palabras, había tantos colegios electorales como distritos. Para las ambiciones presidenciales de un determinado partido político, la distribución de los votos populares entre estos distritos era tan o más importante que el voto nacional global.

En las elecciones para los representantes nacionales, la tasa de voto combinada de los partidos peronista y radical declinó progresivamente desde el 86 por ciento en 1983 hasta el 70 por ciento en 1991 y 65 por ciento en 1995 . Aún más importante, esta declinación de la tasa de voto combinado es regularmente observada en todos los distritos, con pocas excepciones (4). En los cuatro distritos mayores (5) el proceso de desconcentración está ligado al crecimiento electoral y/o la aparición de partidos derechistas e izquierdistas "nacionales". En los distritos medianos el fenómeno de la pluralización y el incremento de la fragmentación es más radical y acusado. Los terceros partidos han emergido y ganado importantes espacios en la política local (6). En Corrientes, Neuquén y San Juan, donde los partidos pro-

(2) Este artículo fue escrito para una conferencia en 1993, antes de las elecciones nacionales de 1993, 1994 (Reforma constitucional) y 1995. Después de estas elecciones, la mayoría de los analistas políticos son conscientes del deterioro del sistema bipartidista. Sin embargo, partiendo de los particularmente malos resultados de los radicales en estas elecciones (especialmente en las elecciones presidenciales de 1995), la principal cuestión es si el radicalismo sería sustituido como segundo partido o no. Influenciados por las victorias electorales del partido peronista, tendieron a ignorar que la tendencia hacia el incremento de la fraccionalización es general.

(3) En Argentina, este proceso es denominado como "despolarización" (De Ritz, L. y Adrogue, G. "Democracia y elecciones en Argentina: 1983-1989 “, en Nohlen, D. y De Riz, L., Reforma institucional y cambio político, Buenos Aires, CEDES, 1991) por la histórica división en la opinión pública entre dos polos políticos: peronismo y antiperonismo (la descripción del "juego imposible", O’Donnell, G . Modernization and Bureaucratic- Authoritarianism, Berkeley: University of California, 1973). Evitaré usar el término "despolarización” en este artículo porque el concepto "polarización" al menos desde el trabajo clásico de Sartori sobre partidos políticos (Parties and Party Sistems, New York: Cambridge University Press, 1976) conlleva una fuerte connotación de un incremento en la distancia ideológica. Por supuesto, la distancia ideológica es un concepto que es muy difícil de definir y de medir en el entorno político construido alrededor de los "partidos atrápalo-todo" y movimientos "nacionalpopulistas "

(4) Catamarca, Entre Ríos, Formosa, La Pampa, La Rioja y San Luis.

(5) Distrito Federal (Capital Federal), Buenos Aires, Córdoba y Santa Fe. Juntos eligen más de la mitad de los representantes nacionales.

(6) Chaco, Tucumán y Salta son los ejemplos más sorprendentes. vinciales habían sido históricamente importantes y ganaron sus correspodientes gobernaciones en 1983 a pesar de la alta "polarización" peronista/radical de los votos populares, estos partidos locales mantuvieron su relativa fuerza electoral (7).

El problema que había surgido era que el sistema electoral argentino no estaba muy bien preparado para tratar con un incremento de la pluralización. Desde 1983, la competición electoral efectiva y el proceso de incremento de la fragmentación podían ser interpretados como unos atributos sistémicos positivos que reforzaban la representatividad del sistema político emergente. La realidad era que estas características habían llegado a ser características potencialmente disruptivas para la estabilidad institucional debido a que el antiguo sistema electoral no estaba preparado para hacerle frente. Si la combinación de un Colegio Electoral presidencial y la representación proporcional era arriesgada, entonces la combinación de un lento pero efectivo proceso de fragmentación y pluralización convirtió esta combinación en una fuente latente de conflictos para la continuidad institucional de la democracia.

Hasta 1994, Argentina seleccionó su presidente mediante el sistema del colegio electoral indirecto, utilizado en los Estados Unidos. Este sistema requiere que una mayoría de electores presidenciales apoye a un candidato para que este candidato obtenga la presidencia. En los Estados Unidos, el principio electoral pluralista empleado en la mayoría de los distritos refuerza la formación de esta mayoría a través de la fórmula de "winner-takes-all" que asigna a los electores presidenciales del distrito al vencedor. En Argentina, el uso de la fórmula de representación proporcional en la distribución de los electores presidenciales en todos los distritos hace que la mayoría necesaria sea más difícil de lograr.

La alta concentración de votos alrededor del peronismo y el radicalismo en 1983, y la pequeña (aunque aún muy importante) tasa combinada de votos de estos dos partidos en 1989, ayudó a formar la mayoría necesaria de electores en el Colegio Electoral, a pesar del principio de la representación proporcional. No obstante, ni el nivel impresionante de fragmentación partidaria ni la radical aparición de un tercer partido nacional fueron necesarias para complicar la elección presidencial y obtener una párálisis electoral. Sólo una pequeña y gradual desconcentración de los votos en algunos distritos (como había estado ocurriendo) fue necesaria para embrollar los resultados de las elecciones presidenciales.

La combinación de un Colegio Electoral bajo principios mayoritarios, distribución proporcional de los electores presidenciales y un proceso de incremento de la pluralización en la mayoría de las provincias (donde las elecciones presidenciales fueron decididas por las complejidades del

(7) En los diez distritos electorales restantes (que eligen juntos menos de una quinta parte de los representantes nacionales) no ha habido un incremento de la fraccionalización. El reducido número de escaños que se distribuyen en ellos (dos o tres por elección) frustra la efectividad de la fórmula de representación proporcional y es una de las razones que explica las secesiones. Los detalles del trabajo empírico para estudiar este proceso pueden ser observados en las siguientes secciones, y las fuentes de los datos electorales son la Dirección Nacional Electoral y De Riz, L. y Adrogue, G., op.cit. 
Colegio Electoral) amenazó la estabilidad de la democracia. Fue una espada de Damócles sobre la continuidad institucional de la república.

\section{UN BREVE RESUMEN DE LAS ELECCIONES NACIONALES}

En 1983 la Unión Cívica Radical obtuvo 52 por ciento del voto popular para su candidato presidencial (Raúl Alfonsín), 48 por ciento para sus diputados nacionales, y sólo un 32 por ciento para las gobernaciones. El Partido Justicialista (peronismo) consiguió el 40 por ciento para presidente, 38 por ciento para los diputados nacionales pero un 54 por ciento de las gobernaciones.

A pesar del hecho de que Alfonsín ganó la elección presidencial en catorce provincias, la UCR sólo pudo ganar elecciones para gobernador en siete provincias. En Corrientes, Neuquén y San Juan, los partidos provinciales obtuvieron las gobernaciones mientras que Alfonsín ganó las elecciones presidenciales. En Catamarca, La Pampa, San Luis y Santa Fé, Alfonsín ganó las presidenciales pero el candidato peronista obtuvo la gobernación.

En el nivel del gobierno nacional, La UCR obtuvo la presidencia y una amplia mayoría en la cámara nacional de diputados (129 representantes de 254). Habiendo ganado en más provincias que los radicales en el nivel de elecciones provinciales, los peronistas recibieron una mayoría en la cámara de senadores (21 de 46) y obtuvieron un importante poder de veto (los radicales obtuvieron sólo 18 senadores) (8).

En 1985 tuvieron lugar las elecciones para renovar la mitad de la Cámara de diputados y la Unión Cívica Radical revalidó su poder electoral. A pesar del declinar en los votos populares (desde el 48 por ciento al 43 por ciento), los radicales ganaron las elecciones en términos nacionales, y los peronistas, divididos por la sorprendente derrota de 1983 e inmersos en una lucha interna, obtuvieron sólo 34 por ciento de los votos (9). Como consecuencia, los radicales mantuvieron su mayoría de 129 escaños en la cámara de diputados.

Las elecciones legislativas provinciales y nacionales de 1987 resultaron ser para los radicales una sorpresa. Su derrota fue mucho más amplia de lo esperado. Históricamente la fuerza de los partidos provinciales retuvo las gobernaciones de Corrientes, San Juan y Neuquén. Los peronistas (ya recuperados de sus luchas y divisiones y liderados por los "Renovadores") no solo retuvieron el control de las provincias ganadas en 1983 sino también añadieron cinco de

(8) Los senadores fueron indirectamente elegidos para las legislaturas provinciales, de acuerdo con la antigua Constitución.

(9) En algunas provincias (fundamentalmente en Buenos Aires) el peronismo se dividió en dos diferentes facciones y presentó dos papeletas diferentes. Después de la derrota de 1983, algunos líderes peronistas (los "renovadores") comenzaron a expresar su desacuerdo con los viejos modos de organización del partido, culpándolos de la derrota. Intentaron una renovación del lenguaje tradicional y de los símbolos del peronismo, adaptándolos a los tiempos de la democracia liberal. Habiendo sido apartados del acceso a posiciones en la estructura oficial del partido, los renovadores participaron en las elecciones bajo la bandera de partidos minoritarios aliados y obteniendo, en general, más votos que la papeleta "oficial" peronista. Comprobaron su fuerza, y desde 1985 en adelante, fue reconocida su superioridad electoral. los siete distritos ganados por los Radicales en las elecciones previas para gobernadores. Los peronistas consiguieron el control de diecisiete gobiernos provinciales y los radicales retuvieron: Córdoba y Río Negro. Como una consecuencia del completo cambio peronista de las provincias, el partido peronista tomó control del Senado. En cuanto a los diputados nacionales, la UCR cayó al 37 por ciento mientras que los peronistas subieron al 41 por ciento (Tabla I). Como consecuencia, los radicales perdieron el control de la Cámara de Diputados. Disminuyeron de 129 a 113 escaños (de un total de 254).

En 1988, el partido peronista organizó elecciones internas democráticas y directas para seleccionar a su candidato presidencial, por primera vez en su historia. Carlos Menem, el gobernador de La Rioja, una pequeña provincial del noroeste, uno de los principales líderes "renovadores", derrotó a Antonio Cafiero, el gobernador de Buenos Aires, la mayor y más rica provincia argentina y bastión histórico del peronismo. En las elecciones presidenciales y legislativas de 1989, la UCR continuó perdiendo apoyo electoral. Menem ganó las elecciones presidenciales obteniendo 47 por ciento de los votos populares (y la mayoría necesaria de votos electorales en el Colegio Electoral) contra un 37 por ciento del candidato presidencial radical, Eduardo Angeloz, gobernador de Córdoba (10). En lo que se refiere a diputados nacionales, la UCR cayó al 29 por ciento mientras los peronistas ascendieron del 41 al 45 por ciento (Tabla I). El partido peronista no obtuvo la mayoría de representantes en la Cámara de Diputados pero los siete votos necesarios para conseguir esa mayoría podían ser negociados con los partidos minoritarios históricamente aliados del peronismo. El Senado permaneció completamente bajo el control del partido peronista.

\section{Tabla I}

TENDENCIA DE CONCENTRACION DE VOTO

\begin{tabular}{lccccccc}
\hline Porcentajes & 1983 & 1985 & 1987 & 1989 & 1991 & 1993 & 1995 \\
\hline UCR Presidenciales & 52 & - & - & 32 & - & - & 17 \\
PJ Presidenciales & 40 & - & - & 47 & - & - & 50 \\
\hline UCR+PJ Presidenciales & 92 & - & - & 79 & - & - & 67 \\
\hline UCR Diputados & 48 & 44 & 37 & 29 & 29 & 30 & 22 \\
PJ Diputados & 38 & 35 & 41 & 45 & 41 & 42 & 43 \\
\hline UCR+PJ Diputados & 86 & 79 & 78 & 74 & 70 & 72 & 65 \\
\hline UCR+PJ Diputados (Bs. As.) & 90 & 78 & 83 & 75 & 67 & 74 & 69 \\
UCR+PJ Gobernador (Bs. As.) & 92 & - & 87 & - & 70 & - & 74 \\
\hline UCR+PJ Diputados (Cap. Fed.) & 73 & 68 & 63 & 60 & 69 & 62 & 43 \\
\hline UCR+PJ Diputados (Tucumán) & 91 & 90 & 60 & 52 & 53 & 62 & 50 \\
UCR+PJ Gobernador (Tucumán) & 89 & - & 79 & - & 54 & - & 50 \\
\hline UCR+PJ Diputados (Chaco) & 94 & 92 & 95 & 83 & 58 & 61 & 72 \\
UCR+PJ Gobernador (Chaco.) & 94 & - & 96 & - & 59 & - & - \\
\hline UCR+PJ Diputados (Jujuy) & 81 & 58 & 78 & 58 & 60 & 63 & 50 \\
\hline UCR+PJ Diputados (Salta) & 87 & 70 & 78 & 66 & 44 & 57 & 47 \\
\hline UCR+PJ Diputados (Corrientes) & 57 & 44 & 43 & 57 & 48 & 48 & 46 \\
\hline UCR+PJ Diputados (Neuquen) & 61 & 64 & 40 & 60 & 44 & 56 & 39 \\
\hline UCR+PJ Diputados (San Juan) & 68 & 72 & 63 & 43 & 40 & 35 & 52 \\
\hline
\end{tabular}

La toma de posesión presidencial de Menem, originariamente fechada en diciembre, fue adelantada a julio debido a la aguda crisis económica. El estallido de la hiperinflación forzó al presidente Alfonsín a renunciar cinco meses antes del fin de su mandato. El nuevo presidente peronista,

(10) C.F.I. electores también votaron por Angeloz. 
cuyas políticas expansionistas eran esperadas, se comprometió personalmente a la estabilización económica. Después de una segunda experiencia hiperinflacionaria en 1990 , fue capaz de reducir la inflación a bajos niveles.

En 1991, la primera elección bajo un presidente peronista desde 1983, dio una pequeña disminución de los peronistas, que recibieron el 41 por ciento de los votos para legisladores nacionales mientras los radicales mantuvieron su 29 por ciento. El 41 por ciento del voto obtenido por los peronistas fue interpretado como una aprobación de la política económica de Menem. Los escaños peronistas se incrementaron hasta 124 (sólo 3 menos de la mayoría, aunque 8 de ellos estaban en completa oposición a las políticas presidenciales). Los peronistas perdieron el control de tres provincias. En dos de ellas (Chaco y Salta) un partido local y en la tercera (Chubut), los radicales ganaron las gobernaciones.

El 3 de octubre de 1993, los argentinos votaron en una elección parcial para la Cámara de Diputados por segunda vez desde la inauguración de la administración de Menem, en julio de 1989 (11).

El beneficiado partido peronista (PJ) obtuvo el 42 por ciento de los votos (65 escaños) e incrementó su número de escaños a 127 (de un total de 257); su principal contendiente, el partido radical (UCR), del presidente saliente Raúl Alfonsín, se aseguró el 30 por ciento de los votos (41 escaños). Los peronistas ganaron en 18 de los 24 distritos.

El gobierno interpretó su victoria como una aprobación popular de su programa económico que puso la astronómica inflación argentina bajo control. Así mismo, el presidente Menem consideró los resultados como un mandato para reformar la Constitución y de ese modo permitirle la reelección (explícitamente prohibida en el texto histórico). Eran necesarios los dos tercios de la Cámara Nacional de Diputados y del Senado para convocar una Convención Constituyente. Los votos radicales eran necesarios para alcanzar esa mayoría, pero los radicales estaban muy reticentes a apoyar las aspiraciones de la reelección presidencial.

Sin embargo, Menem anunció que estaba considerando convocar un plebiscito para mostrar el apoyo popular para la reforma constitucional. Bajo esta presión y la amenaza de un nuevo y más duro colapso electoral, Alfonsín, presidente del partido radical, comenzó una serie de conversaciones entre los dos partidos principales, que concluyeron en un pacto para presentar un programa común para reformar la Constitución. Como consecuencia, la necesidad de una reforma constitucional fue aprobada por el poder legislativo y una elección de representantes nacionales para una Convención Constituyente fue convocada y tuvo lugar en 1994.

La repentina decisión de Alfonsín de detener la fuerte oposición radical a la reelección de Menem y de negociar la reforma constitucional produjo dos consecuencias. Por una parte, el partido radical entró en una amarga lucha interna entre facciones que apoyaban y se oponían a la reforma. Por otro lado, una alianza de peronistas disidentes que habían

(11) Esta elección incluyó dos innovaciones legales. La primera, que los ciudadanos argentinos que vivieran en el extranjero podían votar. La segunda, que el Congreso aprobó en 1991 una ley por la cual las mujeres deben ser favorecidas en las listas con una cuota de al menos 30 por ciento de los candidatos con posibilidades de obtener escaño. abandonado el Partido Justicialista, con socialistas y otras expresiones de la izquierda, logró mayor espacio como oposición al gobierno. Con una mayoría de delegados peronistas y radicales a la Convención, la reforma constitucional fue aceptada y el programa común negociado fue aprobado. Esencialmente, la reelección presidencial, propugnada por los peronistas, y la incorporación de un tercer senador para el segundo partido de cada provincia, impulsada por los radicales, fueron introducidas en la nueva Constitución. El procedimiento para las elecciones presidenciales fue cambiado. El Colegio Electoral fue abolido y una intensa negociación entre peronistas y radicales tuvo lugar para decidir la fórmula electoral para la elección presidencial (12).

En 1995, finalmente, las elecciones nacionales, presidenciales y legislativas, tuvieron lugar bajo la nueva Constitución promulgada en 1994. El presidente Menem obtuvo su reelección con casi el 50 por ciento de los votos y la Unión Cívica Radical experimentó uno de los peores resultados de su historia. El candidato presidencial radical, Horacio Massaccessi, gobernador de Río Negro, obtuvo sólo un 17 por ciento de los votos y fue superado por José Bordón (un disidente del partido peronista y candidato de una alianza de centro-izquierda, de diferentes partidos y fracciones), que consiguió casi un 30 por ciento de los votos. Los peronistas recibieron un 43 por ciento de los votos para los representantes nacionales, obteniendo 72 escaños, formando una mayoría en la Cámara Nacional de Diputados por primera vez desde 1983. El partido radical obtuvo un 22 por ciento de los votos y 28 escaños que sumaron 69 representantes nacionales en la Cámara.

\section{SISTEMA DE PARTIDOS Y FRAGMENTACION}

La mayoría de los analistas han identificado al sistema político argentino desde 1983 como un sistema emergente bipartidista o un sistema multipartidista emergente "polarizado" entre los dos principales partidos (radicales y peronistas). En esta sección muestro que el análisis de las elecciones entre 1983 y 1995 señalan una importante tendencia hacia un sistema multipartista (o, en otras palabras, un incremento del debilitamiento del monopolio del radicalismo/peronismo en la competición electoral). Lo que parece ser un pequeño proceso de fragmentación del sistema de partidos a un nivel nacional del análisis, se revela mucho más importante cuando es observado y desagregado por provincias. Excepto, hasta cierto grado, para la mayoría de los distritos menores donde el sistema bipartidista es estable, el incremento de la fragmentación tiene lugar a lo largo de todo el país.

Tres diferentes características del sistema institucional esconden, desalientan o realzan el proceso de incremento de la dispersión electoral: centralismo encubierto,

(12) Presumiendo que Carlos Menem iba a ganar la elección, los peronistas querían establecer la pluralidad como la formula para ganar la presidencia, mientras los radicales querían una fórmula mayoritaria con una elección a dos vueltas, para permitir a la oposición tener una segunda oportunidad de competir más eficazmente por la presidencia. El resultado final fue una solución intermedia, ya descrita en la primera nota. 
el desaliento a la concurrencia de las elecciones ejecutivas y legislativas,....,y la representación proporcional realza este proceso de fragmentación emergente.

a) Centralismo: puesto que el fenómeno es mucho más dramático e importante en las provincias medianas que en los grandes distritos (especialmente la provincia de Buenos Aires y la Capital Federal), ha sido subestimado, al menos hasta las elecciones de 1991. El polo central del país, la ciudad de Buenos Aires y su provincia, contiene un tercio de la población del país pero la actividad política, económica, social y cultural está fuertemente concentrada en ella. Este hecho produce una sobreestimación de la importancia de la actividad política en el centro de la Nación y una subestimación del desarrollo político menos importante del interior. No obstante, esto es contrario al hecho de que el sistema electoral produce una subrepresentación de los cuatro mayores distritos (para los escaños legislativos y para los electores del Colegio Presidencial) y una sobrerepresentación de todo el resto de los distritos, como veremos en la próxima sección.

b) Elecciones concurrentes: las elecciones presidenciales tienen lugar cada seis años y las elecciones legislativas cada dos años (13), y las elecciones para gobernaciones, cada cuatro años (14). En 1983 todos los puestos fueron elegidos. En 1985, las elecciones fueron principalmente para seleccionar sólo representantes nacionales. En 1983, 1989 y 1995, tanto las elecciones presidenciales como legislativas fueron celebradas juntas y en 1983, 1987, 1991 y 1995, tanto las elecciones legislativas nacionales como a las gobernaciones coincidieron. Puesto que los cargos ejecutivos (presidente y gobernadores) no pueden ser distribuidos por representación proporcional y como la esencia de su elección correspondiente es "winnertakes-all" (15), la concentración de votos sobre los candidatos radical y peronista, en estas elecciones concurrentes tiende a ser más alta y su correspondiente nivel de fragmentación más bajo que aquel de una simple elección de representación proporcional "no-concurrente". Esto es así, cuando el legislativo coincide con las elecciones a cargos ejecutivos y los candidatos para el legislativo compiten por cargos bajo las faldas de sus correspondientes candidatos presidenciales o a gobernador, la concurrencia de elecciones realza la concentración de votos en los candidatos radicales y peronistas y difumina el proceso de incremento de la fragmentación (16). Con todo, las elecciones concurrentes disminuyen el proceso de fragmentación pero no pueden obstruirlo, como se observa en la Tabla I.

c) La representación proporcional es evidentemente uno de los elementos que favorecen al proceso de fragmenta-

(13) La Cámara Nacional de Diputados es renovada por mitades

(14) Los legisladores provinciales, los alcaldes y los representantes locales son elegidos cada dos años en elecciones que coinciden con las principales elecciones nacionales. Sin embargo puede variar en cada provincia.

(15) Digo "la esencia", porque la campaña partidaria y el voto popular trataron la elección para presidente como una competición directa entre candidatos por un cargo. Sin embargo, en realidad, la elección presidencial fue hasta 1994 una competición electoral indirecta mediante colegios electorales provinciales. Los electores presidenciales eran elegidos en cada provincia a través de mecanismos de representación proporcional.

(16) La papeleta es sólo una por partido, incluyendo juntos a los candidatos ejecutivos y legislativos para cada nivel de elección: nacional, provincial y municipal Así pues es necesario cortar físicamente la papeleta para combinar el voto por un candidato presidencial de un partido y por el candidato legislativo de otro partido, por ejemplo. Esta característica realza la influencia presidencial, disminuye la división del voto (y, además, la fragmentación en el nivel legislativo). A pesar de excepciones hay una tendencia histórica hacia el voto completo (dentro de cada nivel de elección). ción. Después del antiguo debate alrededor de la ley de Duverger ("el sistema de mayoría simple y de papeleta única favorece al sistema bipartidista...la representación proporcional favorece al multipartidismo"), la conclusión más extendida es que aunque el sistema electoral no pueda ser considerado una causa determinante de un tipo específico de sistema de partidos, es “...generalmente un acelerador 0 un freno..." del desarrollo del sistema de partidos (17). Más allá de que la representación proporcional acelere la fragmentación o no, no hay duda de que finalmente la representación proporcional es seguida de un continuo decrecimiento en la tasa de voto conjunta de los partidos justicialista y radical desde 1983 en adelante (18).

El proceso de incremento de la competitividad puede ser observado de dos maneras: analizando los resultados electorales nacionales en conjunto y desagregándolos por provincias. Contabilizando los resultados nacionales globalmente, la tendencia al incremento de la decadencia del monopolio de la representación de los dos partidos tradicionales más fuertes puede ser observada dos tipos diferentes de índices:

a) El índice de fragmentación de Rae (19): el índice se incrementa de forma continua desde las elecciones nacionales legislativas de 1983 hasta las de 1991. En 1983 la fragmentación fue de 0.62 , en 1991 , de 0.72 y en 1995 , de 0.74 .

(17) Véase el artículo de Sartori, G. "The influence of Electoral Laws: Faulty Laws or Faulty Methods, and Duverger, M. "Duverger,s Laws: Forty Years Later", en Electoral Laws and Their Politica Consequences, editado por Grofman, B. y Lijphart, A., New York, Agathon Press, 1986. La crítica de Sartori a la ley de Duverger y a las hipótesis de Rae, están basadas en características lógicas y temporales de la causación. Sería imposible que las causas funcionaran en una sóla dirección: un diferente sistema electoral causa diferentes sistemas de partidos. “...El votante está constreñido según donde vota. Sin embargo, ningún sistema electoral puede reducir el número de partidos relevantes a dos en el nivel nacional, a no ser que los mismos dos partidos sean los protagonistas relevantes en todas las circunscripciones... El punto que ha tardado en ser reconocido es, entonces, que los efectos de los sistemas electorales no pueden ser establecidos sin, al mismo tiempo, establecer las propiedades manipuladoras del sistema de partidos como tal..." (Sartori, op.cit.). La representación proporcional no tendría un "efecto multiplicador". De acuerdo con Sartori, "...el argumento correcto es que donde quiera que se ha introducido la representación proporcional sucede que es seguida por el surgimiento de nuevos partidos relevantes, lo que no podemos realmente achacar a los efectos de la representación proporcional sino a los efectos laterales resultantes de la eliminación de obstáculos preexistentes.

(18) La sorprendente ironía es que la combinación de la representación proporcional y de la competición electoral durante diez años está produciendo cambios en el sistema de partidos mientras que las proscripciones y las dictaduras (a pesar de sus intentos por transformar la política y quebrar al populismo) sólo congelaron las situación política y el sistema partidario durante algunos años. Elaborando las definiciones clásicas de Rokkan sobre los clivajes partidarios, Morlino ("Democratic Establishments" en Diamond, L., Linz, J. y Lipset, S., Democracy in Developing Countries: Latin America, Boulder: L. Rienner, 1987) sugiere este "efecto congelador" para algunos regímenes militares latinoamericanos. Durante las dictaduras, alejado el peligro de la competición electoral, antiguas redes de caudillismo y clientelismo sobrevivieron tanto como los propios caudillos. Confrontadas con la competición real, algunas de estas redes se revelaron ineficaces en los tiempos democráticos. Como ejemplo, el Movimiento de Integración y Desarrollo (MID, liderado por el ex-presidente Frondizi ) había sido un partido en decadencia desde 1963. Sobrevivió al régimen militar de 1976-1983 y recibió el 2 ó 3 por ciento de los votos en numerosos distritos en 1983, solamente para casi desaparecer en las siguientes elecciones. En 1983, en Formosa, una provincia tradicional, pequeña y atrasada, el MID fue todavía falsamente identificado con el Movimiento Radical Intransigente, del cual el MID había surgido hacía más de veinte años. Por supuesto, esta fue la original y antigua identificación de los caudillos del movimiento en Formosa. Otra sorprendente ironía es que lo que no pudo hacer el régimen militar mediante la manipulación política de una hipotética transición en 1980-1982 (el agrupamiento de partidos conservadores provinciales para construir una alternativa nacional contra el radicalismo y el peronismo), está comenzando tímidamente a aparecer bajo la competición electoral libre

(19) El concepto original de Rae (The Political Consecuences of Electoral Laws, New Haven: Yale University Press, 1971) de la fragmentación mide (i) el número de cuotas de loR partidos y (ii) la relativa igualdad de estas cuotas. $\mathrm{F}=1-[\mathrm{V}$ ( por ciento)] Los valores de fragmentación ocupan un continuo que va desde la nula fragmentación en un sistema perfecto de partido único $(\mathrm{F}=0)$ hasta la completa fragmentación - fenómeno que nunca ocurre en la realidad ni en la fórmula - definido por el límite de $\mathrm{F}$ cuando vale la unidad. Bajo un sistema bipartidista perfecto, (p.e. 50-50), existe una forma intermedia de fragmentación, y hay la misma oportunidad de que dos votantes elegirán diferentes partidos (por tanto, F igual a 0.50 ). 
El sistema de partidos emergente está continuamente alejándose de un sistema bipartidista clásico $(\mathrm{F}=0.5)$.

b) La cuota combinada de voto de los dos partidos mayoritarios (peronistas y radicales): para las elecciones nacionales legislativas, la cuota combinada de voto contínuamente desciende desde el 86 por ciento en 1983 hasta el 79 por ciento en 1985,78 por ciento en 1987,74 por ciento en 1989 , 70 por ciento en 1991,72 por ciento en 1993 y 62 por ciento en 1995. (Ver Tabla I). Otros partidos han incrementado su fuerza desde un 14 por ciento en 1983 hasta un 30 por ciento en 1991 y un 35 por ciento en 1995. Si comparamos las elecciones presidenciales, el voto combinado ha descendido desde casi el 92 por ciento en 1993 cuando el radical Raúl Alfonsín derrotó al peronista Italo Lúder (y llegó a ser el primer presidente democrático después del régimen militar), hasta el 80 por ciento en 1989, cuando el peronista Carlos Menem llegó a ser el nuevo presidente al derrotar al radical Eduardo Angeloz, y al 67 por ciento en 1995 (Véase Tabla I).

Si desagregamos los resultados electorales nacionales por provincias, el patrón de declinación del voto combinado para los diputados nacionales para los dos partidos más fuertes se observa regularmente en cada provincia, excepto en Catamarca, Entre Ríos, Formosa, La Pampa, La Rioja y San Luis. El proceso de inclusión de nuevos partidos y de incremento de la competición, así como la decadencia del sistema cuasi bipartidista puede ser propiamente desagregado por provincias $\mathrm{y}$, de esta forma, se percibe con mayor detalle y profundidad.

El mapa electoral argentino puede ser dividido en tres diferentes tipos de distritos electorales, de acuerdo a la siguiente escala: (i) los cuatro mayores distritos, Buenos Aires, Capital Federal, Córdoba y Santa Fe, con más de la mitad de la población del país que eligen más de la mitad de los representantes nacionales; (ii) los distritos medianos (Corrientes, Chaco, Entre Ríos, Jujuy, Mendoza, Misiones, Salta, San Juan, Santiago del Estero y Tucumán) eligen entre seis y diez representantes cada uno; (iii) los restantes diez distritos más pequeños juntos eligen menos de la quinta parte de los representates nacionales (Ver tabla II). Aún más complejos (debido a importantes factores históricos) dos de los distritos medianos (Corrientes y San Juan) y uno de los distritos menores (Neuquén) deben ser estudiados por separado. Ellos forman una cuarta categoría porque excepcionalmente los fuertes partidos locales históricamente han sido extremadamente importantes.

El desarrollo del sistema de partidos desde 1983 ha tomado diferentes formas en cada una de estas cuatro categorías de distrito. En los distritos mayores hay un proceso de incremento de la fragmentación que se liga a la declinación de los partidos peronista y radical y al fortalecimiento o aparición de partidos derechistas e izquierdistas nacionales (20). En la Capital Federal (que ya era el distrito más altamente fragmentado en las primeras elecciones de 1983), la fragmentación osciló desde el 0.69 en 1983 al 0.74 en 1971. En este distrito, peronistas y radicales juntos recibieron el 91 por ciento de los votos en la elección presidencial de 1983 pero sólo un 67 por ciento en la elección presidencial de 1989 (Ver Tabla I). En

(20) Los llamo "partidos nacionales" no sólo porque están organizados nacionalmente sino porque sus intereses no están centrados en asuntos locales. Los partidos localistas han aparecido y existen (en diferentes grados) en estos distritos pero se constriñen al nivel municipal sin que formulen políticas al nivel provincial. las siguientes elecciones presidenciales, en 1995, la alianza de centro-izquierda, FREPASO, ganó la elección en el distrito, con el 44 por ciento de los votos. En esta ocasión, radicales y peronistas juntos sólo lograron el 52 por ciento. Para los representantes nacionales, mientras peronistas y radicales juntos descendieron su porcentaje desde el 73 en 1983 al 60 en 1989, y finalmente al 43 en 1995, la UCD, un partido de derechas, consiguió el 18 por ciento en 1987 y el 22 por ciento en 1989 y el Frente Grande, un grupo de centro-izquierda, obtuvo casi el 14 por ciento de los votos en 1993, ganó las elecciones para la Convención Constituyente en el distrito, en 1994, y también ganó la elección (mediante una amplia alianza, FREPASO), en 1995, con el 35 por ciento.

\section{TABLA II}

\section{DIPUTADOS NACIONALES Y ELECTORES} POR DISTRITOS

A. Distribución de acuerdo con el Censo de 1980 empleado en las elecciones nacionales de 1983, 1985, 1987, 1989, 1991, 1993 y 1995

\begin{tabular}{|c|c|c|c|c|c|}
\hline DISTRITO & HABITS. & $\%$ & $\begin{array}{l}\text { DIPUTADOS } \\
\text { NACION. }\end{array}$ & $\begin{array}{l}\text { ELECTORES } \\
\text { PRESID. }\end{array}$ & $\%$ \\
\hline Capital Federal & 2.922 .829 & 10.4 & 25 & 54 & 9.0 \\
\hline Buenos Aires & 10.865 .408 & 38.8 & 70 & 144 & 24.0 \\
\hline Catamarca & 207.717 & 0.7 & 5 & 14 & 2.3 \\
\hline Córdoba & 2.407 .754 & 8.6 & 18 & 40 & 6.7 \\
\hline Corrientes & 661.454 & 2.4 & 7 & 18 & 3.0 \\
\hline Chaco & 701.392 & 2.5 & 7 & 18 & 3.0 \\
\hline Chubut & 263.116 & 0.9 & 5 & 14 & 2.3 \\
\hline Entre Ríos & 908.313 & 3.3 & 9 & 22 & 3.7 \\
\hline Formosa & 295.887 & 1.1 & 5 & 14 & 2.3 \\
\hline Jujuy & 410.008 & 1.5 & 6 & 16 & 2.7 \\
\hline La Pampa & 208.260 & 0.7 & 5 & 14 & 2.3 \\
\hline La Rioja & 164.267 & 0.6 & 5 & 14 & 2.3 \\
\hline Mendoza & 1.196 .228 & 4.3 & 10 & 24 & 4.0 \\
\hline Misiones & 588.977 & 2.1 & 7 & 18 & 3.0 \\
\hline Neuquên & 243.850 & 0.9 & 5 & 14 & 2.3 \\
\hline Río Negro & 383.354 & 1.4 & 5 & 14 & 2.3 \\
\hline Salta & 662.870 & 2.4 & 7 & 18 & 3.0 \\
\hline San Juan & 465.976 & 1.7 & 6 & 16 & 2.7 \\
\hline San Luis & 214.416 & 0.8 & 5 & 14 & 2.3 \\
\hline Santa Cruz & 114.941 & 0.4 & 5 & 14 & 2.3 \\
\hline Santa $\mathrm{Fe}$ & 2.465 .546 & 8.8 & 19 & 42 & 7.0 \\
\hline Sgo. de Estero & 594.920 & 2.1 & 7 & 18 & 3.0 \\
\hline Tucumán & 972.655 & 3.5 & 9 & 22 & 3.7 \\
\hline Tierra del Fuego & 29.392 & 0.1 & 2 & 4 & 0.7 \\
\hline TOTAL & 27.949 .480 & 1000 & 254 & 600 & 999 \\
\hline
\end{tabular}

B. Distribución de acuerdo con el Censo de 1991

\begin{tabular}{|c|c|c|c|c|c|}
\hline DISTRITO & HABITS. & $\%$ & $\begin{array}{l}\text { DIPUTADOS } \\
\text { NACION. }\end{array}$ & $\begin{array}{l}\text { ELECTORES } \\
\text { PRESID. }\end{array}$ & $\%$ \\
\hline Capital Federal & 2.995 .002 & 9.2 & 25 & 54 & 8.3 \\
\hline Buenos Aires & 12.538 .007 & 38.7 & 81 & 166 & 25.5 \\
\hline Catamarca & 264.940 & 0.8 & 5 & 14 & 2.1 \\
\hline Córdoba & 2.761 .067 & 8.5 & 20 & 44 & 6.7 \\
\hline Corrientes & 780.778 & 2.4 & 8 & 20 & 3.1 \\
\hline Chaco & 799.302 & 2.5 & 8 & 20 & 3.1 \\
\hline Chubut & 324.582 & 1.0 & 5 & 14 & 2.1 \\
\hline Entre Ríos & 1.021 .042 & 3.1 & 9 & 36 & 5.5 \\
\hline Formosa & 380.205 & 1.2 & 5 & 14 & 2.1 \\
\hline Jujuy & 513.213 & 1.6 & 6 & 16 & 2.4 \\
\hline La Pampa & 258.334 & 0.8 & 5 & 14 & 2.1 \\
\hline La Rioja & 220.910 & 0.7 & 5 & 14 & 2.1 \\
\hline Mendoza & 1.400 .142 & 4.3 & 12 & 28 & 4.3 \\
\hline Misiones & 779.089 & 2.4 & 8 & 20 & 3.1 \\
\hline Neuquén & 385.606 & 1.2 & 5 & 14 & 2.1 \\
\hline Río Negro & 506.314 & 1.6 & 5 & 14 & 2.1 \\
\hline Salta & 863.688 & 2.7 & 8 & 20 & 3.1 \\
\hline San Juan & 526.263 & 1.6 & 6 & 16 & 2.4 \\
\hline San Luis & 272.896 & 0.8 & 5 & 14 & 2.1 \\
\hline Santa Cruz & 159.726 & 0.5 & 5 & 14 & 2.1 \\
\hline Santa Fe & 2.782 .809 & 8.6 & 20 & 44 & 6.7 \\
\hline Sgo. de Estero & 670.388 & 2.0 & 7 & 18 & 2.8 \\
\hline Tucumán & 1.136 .545 & 3.5 & 10 & 24 & 3.7 \\
\hline Tierra del Fuego & 69.450 & 0.2 & 5 & 14 & 2.1 \\
\hline TOTAL & 32.370 .298 & 100.0 & 278 & 652 & 100.0 \\
\hline
\end{tabular}


En la provincia de Buenos Aires, la declinación del voto combinado de peronistas y radicales fue del 93 por ciento (1983) al 79 por ciento (1989) y 66 por ciento (1995) en las elecciones presidenciales. La fragmentación se incrementó desde el 0.59 en 1983 , hasta el 0.68 en 1989 y el 0.73 en 1991. En las elecciones para gobernador en Buenos Aires, peronistas y radicales juntos recibieron el 92 por ciento del voto en 1983 (cuando el radical Armendáriz llegó a ser gobernador en el bastión histórico del peronismo), 87 por ciento en 1987 (cuando el peronista Cafiero recuperó la provincia para su partido) y sólo un 70 por ciento en 1991 . Para las elecciones legislativas el decrecimiento del voto combinado de los dos partidos más fuertes fue desde el 89 por ciento en 1983 hasta el 68 por ciento en 1991 y el 70 por ciento en 1995 (Ver Tabla I).

En Santa $\mathrm{Fe}$, peronistas y radicales juntos, obtuvieron 88 por ciento de los votos para diputados nacionales en las elecciones de 1983 y solamente un 62 por ciento en 1991 , cuando una coalición de partidos socialistas obtuvo un 17 por ciento. La fragmentación se incrementó todavía más en 1995, cuando el FREPASO obtuvo el 28 por ciento y la Democracia Progresista, el 9 por ciento. Radicales y peronistas juntos sólo alcanzaron un 51 por ciento.

Sin embargo, es en las provincias medianas donde el fenómeno del incremento de la dispersión electoral y de la emergencia de terceros partidos locales de derechas tuvo el efecto más dramático (21). En Chaco, Salta, Tucumán y Jujuy, los partidos políticos locales, ligados al pasado régimen militar han aparecido y ganado importantes espacios en el espectro político. Ayudados por las críticas situaciones económicas de las provincias y la fricción con el gobierno central, en Chaco, Alianza Acción Chaqueña, liderada por el ex-alcalde de la capital durante la dictadura, llegó a ser el primer partido en 1991. En Tucumán, Fuerza Republicana, liderada por el general Bussi, un ex-gobernador militar,obtuvo el 35 por ciento en 1989 y el 44 por ciento en 1991 y ganó las elecciones provinciales en 1995, convirtiéndose en el primer partido de la provincia y ganando la gobernación para Bussi por primera vez. En Jujuy, un partido local tradicional, el Movimiento Popular Jujeño (MPJ) creció desde el 15 por ciento en las legislativas de 1983 hasta el 27 por ciento en las legislativas de $1991 \mathrm{y}$, al mismo tiempo, Fuerza Republicana también apareció recibiendo alrededor del 10 por ciento de los votos en 1989 y 19991. Ambos partidos repitieron sus resultados electorales en 1993 y 1995. En Salta, el Partido Renovador, habitualmente liderado por un militar, creció desde un 6 por ciento en 1983 hasta la mayoría del voto (57 por ciento) en 1991. Para representantes nacionales obtuvo el 34 por ciento de los votos en 1993 y 1995. En Mendoza, el histórico Partido Demócrata mantuvo su 15 por ciento a lo largo de estos doce años.

Solamente en los pequeños distritos, en general, no ha habido un proceso de incremento de la fragmentación. Estas zonas del país han sido una excepción el proceso de incre-

(21) El impacto puede ser apreciado en la Tabla I. Los partidos provinciales oscilaron entre el 4 por ciento del total nacional de votos en 1989 y el 15 por ciento en 1991. Otros partidos, distintos a peronistas y radicales, aumentaron desde el 10 por ciento en 1983 hasta el 30 por ciento en 1991. mento de los nuevos partidos (22). Los partidos radical y peronista mantienen su dominio en la mayoría de los pequeños distritos. Debido posiblemente a razones históricas, socio-económicas y políticas, hay un impedimento institucional: en estos pequeños distritos de sólo cinco escaños, cada dos años una elección distribuye dos o tres escaños nacionales en el distrito. La fórmula electoral de representación proporcional no puede asignar proporcionalmente esta pequeña cantidad de escaños con eficacia y se convierte, de facto, en una fórmula no proporcional (23). Los terceros partidos no se muestran muy animados a participar en las elecciones nacionales en estos distritos. Generalmente, el partido más fuerte consigue uno o dos escaños y el segundo partido más votado consigue el resto de los escaños, más allá de su cuota de voto, la diferencia de votos y la cuota del tercer partido (24).

En Corrientes, San Juan y Neuquén, un partido provincial históricamente importante ha mantenido su fuerza durante todas las elecciones. Al igual que en el período previo a las elecciones que comenzaron a partir de 1983, el sistema de partidos de estas provincias no ha sido ni un sistema emergente bipartidista ni tampoco un sistema multipartidista altamente concentrado en peronistas y radicales. Los sistemas de partidos de Corrientes, San Juan y Neuquén son claramente sistemas tripartidistas, como eran en 1983. Al mismo tiempo, aunque el aplastante poder electoral de Alfonsín le permitió obtener una victoria en las elecciones para presidente en cada una de estas tres provincias, la Unión Cívica Radical no pudo evitar que el Pacto Autonomista-Liberal (PAL), el Movimiento Popular Neuquino (MPN) y el Bloquismo ganaran las elecciones en el nivel provincial y obtuvieran las gobernaciones y los senadores nacionales en Corrientes, Neuquén y San Juan respectivamente. Los tres partidos habían oscilado entre un 30 y un 60 por ciento en todas las elecciones. Los peronistas y radicales juntos recibieron menos del 50 por ciento de los votos en cada provincia, en las elecciones legislativas de 1991 (Ver Tabla I) (25).

La combinación de (i) el mantenimiento del poder electoral de los tres antiguos partidos provinciales históricos,

(22) Una de las pocas excepciones a este patrón es la pequeña provincia de Tierra del Fuego (territorio nacional hasta 1992). Allí, el Movimiento Popular Fueguino convirtió su 20 por ciento de 1983 en un 38 por ciento en 1991.

(23) “... Cualquier elección de representación proporcional en pequeños distritos es en la práctica una elección mayoritaria..." (Nohlen, D.: "Los sistemas electorales entre la ciencia y la ficción”, en Opciones, $\mathrm{N}^{\circ} 4$, Santiago, 1984). “...Magnitudes muy pequeñas de, digamos, tres escaños, frustran la precisión del efecto de la fórmula de representación proporcional en la práctica..." (Rae, op.cit.).

(24) Catamarca (en el noroeste) es una de estas pequeñas provincias y es un ejemplo de esta excepción a la tendencia nacional de incremento de la fragmentación: el índice de fragmentación de Rae se sitúa alrededor del 0.5 en cada elección.

(25) En Corrientes, el histórico Pacto Autonomista-Liberal, con el 47 por ciento del voto popular, ganó la gobernación en 1983 (también recibió el 35 por ciento para los representantes nacionales en una elección nacional altalmente polarizada). En 1985 , su cuota de voto creció hasta casi el 50 por ciento y mantuvo estos resultados en 1987, obteniendo de nuevo la gobernación. Alcanzó más del 40 por ciento de los votos en 1989, 1991, 1993 y 1995, obteniendo la mayoría. En Neuquén, aunque el Movimiento Popular Neuquino, ganó la mayoría en las elecciones provinciales de 1983, no pudo evitar la "polarización" nacional y recibió sólo un 34.5 por ciento del voto para representantes nacionales (segundo lugar). Tanto en 1987 como en 1991, ganó la gobernación nuevamente (con mayoría de votos en la seguna oportunidad). La "nacionalización" de las elecciones provinciales y el "efecto de arrastre" no le perjudicó en 1991, 1993 y 1995, cuando el Movimiento Popular Neuquino ganó también las elecciones para representantes nacionales. En San Juan, aunque decreció en votos y perdió la gobernación obtenida en 1983, el Partido Bloquista todavía conserva el 25 por ciento de los votos. 
(ii) una lenta dispersión electoral en los distritos mayores en favor de la derecha y la izquierda "nacional" y (iii) una exploción de partidos locales extremadamente conservadores en los distritos medianos, está silenciosa y progresivamente está forjando un sistema de partidos levemente diferente.

Aunque hubo una lenta tendencia hacia el descenso de la concentración del voto en peronistas y radicales, los cambios políticos en términos nacionales para los dos partidos históricamente más fuertes no han aparecido hasta 1995 (26). En mayo de 1995, el FREPASO, una alianza centroizquierdista de peronistas disidentes, socialistas y otros socialdemócratas y grupos izquierdistas, obtuvo un 22 por ciento de los votos. Todavía está por verse si la alianza puede desarrollarse hasta llegar a ser un tercer partido nacional y una alternativa a la política nacional tradicional. No obstante, la tarea más difícil para el FREPASO podría ser expandir su fuerza electoral desde los distritos urbanos mayores a las áreas de menor densidad de población y las medianas y pequeñas provincias.

\section{COLEGIO ELECTORAL, REPRESENTACION PROPORCIONAL Y FRAGMENTACION: UNA ESPADA DE DAMOCLES}

En esta sección, se mostrará que la creciente fragmentación estudiada podría haber llegado a ser una amenaza a la estabilidad del nuevo régimen político, a la luz de un complejo sistema electoral que no estaba muy bien preparado para ello. El incremento de la fragmentación aumentó las posibilidades de que sucedieran dos consecuencias muy problemáticas que podrían emerger debido a la extraña combinación del Colegio Electoral presidencial y la representación proporcional: a) La paradoja de una mayoría ganadora de los votos populares que podría perder la elección presidencial por los votos electorales; o b) una complicada parálisis electoral. El Colegio Electoral creó la posibilidad de la paradoja ("loosing mayority winner"); la representación proporcional (y la sobrerrepresentación de distritos menores) no sólo incrementó aquella posibilidad sino que también desarrolló la segunda consecuencia problemática, una parálisis electoral. Si la fragmentación continuaba evolucionando y no había mayoría ganadora (de los votos electorales) en el Colegio Electoral, la combinación de las tres características podría haber complicado inmensamente la elección presidencial.

\section{A. Colegio Electoral}

Hasta 1994, el presidente en Argentina era elegido mediante el sistema indirecto de un Colegio Electoral. Basada en la Constitución norteamericana, la Constitución Nacional

(26) En 1985 un boom de casi un millón de votos (6 por ciento de los votos nacionales) hizo que el izquierdista Partido Intransigente (originariamente surgido de UCR-UCRI), llegó a ser un partido político prometedor. En 1987, su fuerza ya había declinado. En 1989, la derechista Alianza de Centro consiguió casi el 7 por ciento del voto nacional. argentina de 1853 introdujo una serie de colegios electorales (uno por distrito electoral) para elegir al presidente.

El colapso del régimen militar en 1982 y el retorno a las elecciones marcó el comienzo del presente régimen político democrático. A diferencia de la anterior retirada de la dictadura en 1973, cuando las elecciones presidenciales directas fueron organizadas alterando la Constitución, en 1983, la siguiente transición fue conducida como un retorno pleno a la norma constitucional (27).

Sin embargo, cuando el pueblo votó en las elecciones presidenciales de 1983 y 1989 , no votaron directamente por un candidato presidencial sino por una lista de electores presidenciales quienes, después, votaron al presidente. La Constitución de 1853 (artículo 83), requirió una mayoría de votos electorales para el candidato que llegara a ser presidente (si no había mayoría, la decisión tenía que ser tomada por el Congreso). Este proceso de formación de los colegios electorales y de la elección indirecta creó un cúmulo de problemas teóricos en las elecciones presidenciales. Entre ellos, el más importante fue la posibilidad creada artificialmente de que un partido podía ganar una mayoría de votos populares en la nación y podía perder la elección en el Colegio Electoral (28). ¿Cómo podría ocurrir esto?

Tanto en Argentina como en los Estados Unidos no había sólo un único Colegio Electoral Nacional sino tantos colegios como distritos electorales. Aunque había un procedimiento proporcional para asignar a los electores presidenciales entre los distintos distritos electorales (estados o provincias), el número de electores que correspondió a cada distrito no reflejó exactamente el peso real del distrito en la Nación (para una relación entre el porcentaje de población respecto al total, ver Tabla II) (29). El número de electores que correspondió a cada distrito es la suma del número de representantes y senadores de cada distrito en los Estados Unidos y fue el doble de esta suma en el caso Argentino. Aunque los representantes nacionales eran proporcionalmente distribuidos por distritos, la suma de electores

(27) En 1973, el régimen militar organizó las elecciones presidenciales mediante un sistema de ballotage. Si la mayoría no era conseguida en las elecciones, una segunda vuelta tendría lugar para elegir presidente entre los dos candidatos más votados. Por un lado, los militares quisieron forzar una coalición electoral anti-peronista de facto para derrotar al peronismo de esta manera. Por otra parte, el propio Perón fue proscrito como candidato. Accesoriamente, esto demostró la diferencia de fuerzas y prerrogativas en la decadencia de ambos militares (en 1973 y en 1983). Los militares tuvieron menos poder después de la guerra de las Malvinas en 1982, cuando no pudieron imponer sus condiciones para que la democratización tuviera lugar (fundamentalmente una amnistía para los violadores de los derechos humanos). En 1973, Perón logró ganar de todas maneras. El partido peronista ganó las elecciones presidenciales y Cámpora fue presidente. Perón retornó desde el exilio y después de una compleja serie de renuncias del Presidente, el Vicepresidente y miembros del legislativos, otra elección presidencial tuvo lugar y Perón fue finalmente elegido presidente.

(28) Otros problemas legales complejos fueron: (i) los electores podían votar por cualquier persona legalmente capacitada para ser presidente, que no necesitaba ser un candidato antes de la elección, es decir, los electores podían romper su promesa de voto hacia su supuesto candidato de partido; (ii) la abstención o ausencia de los electores no estaba contemplada en la Constitución; y (iii) hubo problemas legales de definición de quórum en los colegios electorales, tanto de la elección para presidente como para la Cámara. (Ver Molinelli, N.: Presidentes y Congresos en Argentina, Buenos Aires, GEL, 1991).

(29) En el caso argentino, la sobrerrepresentación fue aumentada por las leyes electorales anteriormente descritas. La Tabla II muestra la enorme desproporción entre distritos. El número de votos requeridos para obtener tanto un elector legislativo como presidencial mediante la representación proporcional era mucho más pequeña en las provincias sobrerrepresentadas que en los cuatro distritos mayores.Como ejemplo, teóricamente, un voto para legisladores nacionales era 6,6 veces más poderoso en la pequeña provincia sureña de Santa Cruz en la altamente despoblada Patagonia, que en la provincia de Buenos Aires. 
(correspondiente al número de senadores de cada distrito), cuatro en el caso argentino, claramente favoreció a los distritos menos poblados, sobrerrepresentándolos en el Colegio Electoral (Tabla II). Segundo, y más importante, los electores presidenciales no eran elegidos en base a porcentajes nacionales de votos de cada partido en la Nación sino de acuerdo a los porcentajes de votos obtenidos en cada distrito individual (30).

Ambos factores hacen posible la paradoja de que un candidato presidencial pueda obtener la mayoría de los votos populares en la Nación pero no obtenga la mayoría de los votos electorales en el Colegio, debido a la distribución específica de sus votos entre los distritos. Mientras en los Estados Unidos, el sistema mayoritario electoral (winnertakes-all) en el conjunto de los distritos facilita la formación de una mayoría de electores, haciendo que esta paradoja sea una remota posibilidad, en Argentina, debido a la representación proporcional es bastante más posible que ocurra (31).

\section{B. Colegio Electoral más representación proporcional}

El artículo 81 de la Constitución Nacional argentina de 1853, estableció que la elección de los electores presidenciales que forman los Colegios Electorales, debía ser efectuada bajo las mismas condiciones y reglas que las elecciones para diputados nacionales. Cuando se retornó a la ley constitucional, Argentina también retornó a la representación proporcional que había sido usada desde 1963.

El 23 de junio y 12 de julio de 1983, con el consenso de los principales partidos de la oposición, el último presidente militar, general Bignone, promulgó los decretos número 22.838 y 22.847 por los cuales las reglas electorales esenciales fueron establecidas. Estos dos decretos continúan vigentes en la ley electoral argentina y nunca han sido reformados por el Congreso.

El decreto 22.838 instituyó la fórmula electoral D'Hont de representación proporcional. El decreto 22.847/83 transformó la magnitud de los distritos electorales. La Constitución Nacional de 1853 reguló el número de representantes correspondientes a cada distrito electoral de acuerdo a su población (para ser determinado cada diez años a través del Censo Nacional). El decreto 22.847 arbitrariamente añadió tres representantes al número correspondiente a cada distrito electoral e instituyó una representación mínima de cinco diputados nacionales por distrito (32). Esta transformación de la magnitud

(30) Aumentando la posible desproporcionalidad entre los votos populares y el número de electores presidenciales, la mayoría de los estados en los EE.UU. asignan todos los electores a la mayoría ganadora.

(31) Esta paradoja puede tener lugar tanto en Argentina como en Estados Unidos. Un candidato puede perder en votos populares y ganar en votos electorales consiguiendo la presidencia. En 16 Estados de los EE.UU. y en el distrito de Columbia hay leyes que obligan a los electores a votar a la mayoría ganadora por el voto popular en el Estado. Hay un debate sobre la constitucionalidad de estas leyes, que nunca ha sido probada. E 1888, Cleveland ganó en votos populares pero fue derrotado por Harrinson en votos electorales. En 1916, 3.807 votos para Hughes en California podrían haberle dado la presidencia a pesar del hecho de que Woodrow Wilson obtuvo una mayoría de votos populares. En Argentina esto nunca ocurrió. Sin embargo, desde 1963, la representación proporcional hizo que esta paradoja resultara más probable. Sin embargo ningún presidente de los Estados Unidos ha obtenido menos del 50 por ciento de los votos en este siglo (ayudado por los colegios electorales estatales "winner-takes-all"), ésto ocurrió dos veces en Argentina, en 1916 y 1963 (Molinelli, op.cit.)

(32) El Territorio Nacional de Tierra del Fuego fue excluido de este mínimo, asignándosele dos escaños. de los distritos electorales inmediatamente produjo un fenómeno de subrepresentación de los cuatro mayores distritos y una sobrerrepresentación del resto de las provincias (Tabla II).

La desproporcionalidad entre los diferentes distritos producida por el decreto 22.847 en la elección de diputados nacionales fue directamente trasladada y aumentada por la elección de electores presidenciales. Esto ocurrió porque el número de electores presidenciales de cada distrito tenía que ser el doble de la suma de representantes y senadores correspondientes a estos distritos. El mínimo establecido de cinco representantes automáticamente produjo un mínimo de 14 electores para los distritos más pequeños (dos veces la suma de cinco representantes y dos senadores). Los tres representantes adicionales por distrito produjeron seis electores más en los distritos medianos frente a los distritos mayores. (Tabla II) (33).

Sin embargo, la repercusión de la elección presidencial fue una enorme desproporcionalidad entre el número de electores presidenciales y el tamaño de los distritos electorales (ver Tabla II). En la provincia de Buenos Aires, más de 10 millones de habitantes ( 38.8 por ciento) eligieron 144 electores presidenciales ( 24 por ciento), mientras que en Santa Cruz sólo 114.941 habitantes $(0,4$ por ciento) tenían 4 votos electorales (2,3 por ciento). En 1983 y 1989, las elecciones presidenciales, en la sureña provincia de Santa Cruz los votantes tenían aproximadamente nueve veces más de poder electoral que los votantes de Buenos Aires (el mayor distrito, ver Tabla II).

La sobrerrepresentación de los distritos (decreto 22.847) incrementó la probabilidad de la paradoja de que un candidato gane las elecciones mediante los votos populares pero sea incapaz de la mayoría requerida por los votos electorales $y$, por tanto, pierda la presidencia. Por otra parte, el incremento general en el número de electores por distrito (decreto 22.847) disminuye la eficiencia de la representación proporcional puesto que la eficacia de la fórmula electoral dependen fundamentalmente de la magnitud del distrito (34).

Por último, si la fórmula de representación proporcional tiende de forma más eficiente a producir resultados proporcionales, el riguroso requerimiento de la obtención de una mayoría (no una pluralidad) de votos electorales para elegir al presidente era teóricamente mucho más difícil de satisfacer (35). Si la representación proporcional funcionó eficazmente, junto con la sobrerrepresentación

(33) Molinelli, N.G. Colegios Electorales y Asambleas Legislativas. 1854-1983. Buenos Aires, Manantial, 1939. He estudiado el efecto de esta transformación en las magnitudes de los distritos sobre la proporcionalidad del sistema electoral para las elecciones legislativas en "La cuestión de la proporcionalidad y las elecciones legislativas en Argentina" en Revista Mexicana de Sociología, Año LIV, N ${ }^{\circ}$, México, 1992

(34) “... las magnitudes muy pequeñas de, digamos, tres escaños, pueden desvirtuar la precisión de la fórmula de representación proporcional en sus efectos prácticos. Magnitudes mayores de, digamos, 15 escaños pueden permitir que la precisión de la fórmula de representación proporcional se aproxime a la proporcionalidad más estrechamente..." (Rae, op.cit.).

(35) Esta es una de las más grandes diferencias entre el Colegio Electoral en Estados Unidos y en Argentina. En los Estados Unidos la pluralidad de los votos electorales "winner-takes-all" trabaja en el sentido de dificultar la formación de una mayoría. En Argentina, la representación proporcional está de alguna forma en contradicción con el requisito estricto de la regla mayoritaria en el Colegio Electoral. Era el establecimiento de dos principios contradictorios de representación en el proceso de selección presidencial. Era el peligroso resultado del concepto sociológico de Latinoamérica como un "museo viviente" dentro del dominio institucional: el solapamiento de dos principios inconsistentes de representación, cada uno dominante en un período histórico diferente. 
de los distritos, hizo mucho más difícil obtener una mayoría de electores presidenciales (36). Si ningún partido obtenía una mayoría de votos electorales, se abría el proceso para solicitar los votos de los electores para formar una mayoría en el Colegio Electoral. Si ninguna mayoría se obtenía a través del voto del Colegio Electoral, la decisión debía ser tomada por el Congreso. En cualquier caso, el hecho de que ningún partido hubiera obtenido una mayoría podría complicar enormemente la elección presidencial y podría llevar hacia alguna de las siguientes tres situaciones (tanto en el Colegio Electoral como después en el Congreso); todas ellas extremadamente peligrosas para la continuidad institucional:

(i) Los segundos, terceros y otros partidos minoritarios, individualmente o juntos, podrían haber aceptado la pluralidad ganadora como la legitimación del presidente, ayudándole a formar la mayoría (o absteniéndose) para darle la presidencia. Esta fue la "solución chilena" de 1970. El Congreso eligió al Presidente Allende pero la oposición, (principalmente los demócratas cristianos) nunca aceptaron las consecuencias de su propia opción.

(ii) Algunos de estos partidos perdedores podrían haberse aliado para formar una mayoría que desplazara a la pluralidad ganadora y situaran su propio candidato negociado. Esta fue la solución boliviana de 1989 cuando Sánchez de Losada (MNR) ganó la pluralidad en las elecciones pero no obtuvo la mayoría. Una alianza entre segundo partido (la ADN de Banzer) y el tercer partido (MIR) eligió en el Congreso al último candidato Paz Zamora como presidente. La aceptación de este tipo de solución por la población a la larga pareció ser muy difícil en el caso Argentino, donde existe una alta "polarización" entre peronistas y radicales y una historia de engañosas manipulaciones políticas.

(iii) Una completa parálisis. Esto es lo que ocurrió en Bolivia en 1979, cuando Siles Suazo ganó las elecciones sin mayoría, desplazando la elección presidencial al Congreso, donde se realizó un compromiso. Sin embargo, la debilidad de las bases de este tipo de pacto trajo una serie de intervenciones militares que resultaron en nuevos puntos muertos.

Se ha demostrado que esta extraña combinación de una elección presidencial indirecta (mediante Colegios Electorales), un requisito mayoritario en el Colegio Electoral, una representación proporcional para distribuir los votos electorales y una importante desproporcionalidad entre los distritos, complicó drásticamente las elecciones presidenciales, al menos a un nivel de análisis teórico.

(36) La dificultad de obtener una mayoría es también un reflejo del número de partidos que participan en la elección. Aunque el sistema electoral no puede ser considerado la causa del número de partidos que participan en la elección, desempeña un papel en el favorecimiento o no de la participación. En los Estados Unidos, la fórmula electoral "winner-takes-all" es un obstáculo para la participación de un tercer partido. Sin embargo, facilita la obtención de la mayoría. Los votos para electorales presidenciales en Argentina fueron distribuidos en cada distrito bajo la representación proporcional desde 1983. Por eso, los terceros partidos fueron menos desfavorecidos a la hora de participar en la elección presidencial. Podrían tener un poder increíble de negociación en el Colegio Electoral si ninguno de los dos partidos principales conseguía allí la mayoría. Podrían intercambiar su apoyo para la elección del presidente (la fuente principal de patronazgo y clientelismo)

\section{El Colegio Electoral más la representación proporcional más el incremento de la fragmentación}

Este puzzle teórico originado en el sistema institucional nunca ha distorsionado el proceso de elección presidencial en Argentina. Cuando hubo elecciones presidenciales siempre existió una solución mayoritaria en el correspondiente Colegio Electoral y el presidente electo lo ha sido siempre por mayoría o por la pluralidad ganadora de los votos populares. ¿Por qué se ha analizado el puzzle teórico si nunca ocurrió? Primero, el sistema electoral no crea resultados. Los materiales políticos por excelencia, partidos y elecciones, son los inputs decisivos. Ninguna elección puede ser completamente alterada por un específico sistema electoral (37). En este sentido, a lo largo de la historia argentina del presente siglo de hegemonía política de un partido dominante hasta 1983 (radicalismo hasta 1945, peronismo hasta 1983) y una emergencia de un sistema cuasi bipartidista en 1983, ayudó a satisfacer la estricta condición de una mayoría en el Colegio Electoral. Segundo, la representación proporcional fue recién incorporada en 1963 y sólo tres elecciones presidenciales $(1963,1983$ y 1989) se llevaron a cabo con la peculiar combinación del requisito mayoritario en el Colegio Electoral y la representación proporcional para asignar electores en cada distrito.

En la totalidad de los diez colegios electorales de las elecciones presidenciales desde 1916 (con la excepción de 1963, cuando el peronismo dominante fue proscrito) el ganador obtuvo más de un 45 por ciento de los votos populares y que le proporcionaron más del 53 por ciento de los votos electorales. Sólo en 1916 y 1963 la pluralidad ganadora de las elecciones presidenciales necesitó electores prestados para obtener la mayoría requerida. En 1916, Hipólito Yrigoyen, con el 46 por ciento de los votos populares obtuvo el 44 por ciento de los electores y necesitó el apoyo de los disidentes radicales de Santa Fé para alcanzar una mayoría en el Colegio Electoral. Con la representación proporcional, el peronismo proscrito y alrededor del 25 por ciento de votos en blanco, en 1963, el Presidente Illia también necesitó el apoyo de los electores de otros partidos políticos para obtener una mayoría de votos electorales.

No obstante, por otra parte, las leyes electorales pueden ejercer un importante efecto sobre los resultados electorales (como ha sido demostrado indirectamente en esta sección) $y$, por otro lado, el importante proceso de incremento de la fragmentación que había tenido lugar en Argentina desde 1983 podría haber llegado a ser el detonador de un complejo impasse institucional. Para complicar la elección presidencial y para obtener una parálisis electoral impresionante, no era necesario que apareciera un tercer partido fuerte a nivel nacional. Porque la extraña combinación de representación proporcional, Colegio Electoral y desproporcionalidad entre distritos, pequeños incrementos en la fragmentación en los mayores distritos combinado con repentinas apariciones de terceros partidos locales en las provincias medianas y el mantenimiento de los ya existentes sistemas

(37) Como estableció Rae, el efecto de desfragmentación de las leyes electorales sobre las posiciones competitivas de los partidos políticos en las legislaturas es marginal en comparación con los efectos de los resultados electorales. 
tripartidistas provinciales, podría llegar a ser una amenaza a la pacífica resolución de la elección presidencial.

Sólo 24 votos electorales de un total de 600 no pertenecían a los candidatos peronista o radicales en las elecciones presidenciales de 1983, cuando Alfonsín llegó a ser presidente. Seis años después, en 1989, cuando Menem ganó las elecciones presidenciales, 86 electores no eran ni radicales ni peronistas. Sin embargo, con el proceso descrito de incremento de la fragmentación (que creció aún más en 1991), la distribución de los electores presidenciales podría haber sido todavía más desigual en el futuro. Si la fragmentación solamente se incrementó hasta el punto de que el ganador presidencial no pudo obtener su propia mayoría de votos electorales, la competición electoral real podría contradictoriamente llegar a ser una amenaza a la estabilidad del sistema institucional (38).

\section{CONCLUSION}

Después de la debacle del régimen militar en 1982, la Argentina comenzó un nuevo régimen polítito basado en elecciones libres para seleccionar a los gobernantes. Este nuevo régimen político a sobrevivido a cuatro rebeliones militares, dos procesos de hiperinflación y dos motines populares por hambre. Algunas de las características políticas del actual régimen lo hacen muy diferente de las experiencias semidemocráticas previas, entre ellas, la amplia deslegitimación de los militares en la historia y la competición real electoral.
La competición electoral actual comenzó a suceder después de una pérdida de hegemonía política de un partido dominante. No obstante he mostrado que un proceso contemporáneo de incremento de la fragmentación de la competición electoral era no sólo una característica reforzante de la democracia, sino también y contradictoriamente, puede llegar a ser una amenaza a la estabilidad del sistema institucional.

La combinación del Colegio Electoral con el principio de la mayoría, la representación proporcional para la designación de los electores presidenciales, la desproporcionalidad y el incrememento de la fragmentación de la competición política (especialmente a nivel provincial) estaba poniendo en riesto la estabilidad y continuidad del régimen democrática.

Fue en este esquema que el análisis institucional fue importante y la Convención Constituyente abolió el Colegio Electoral en 1994. Confiar en la "ingeniería” institucional como la principal esperanza y factor que asegure la continuidad de la democracia podría haber sido muy ingenuo. Así como también podría ser ingenuo explicar la democracia y la estabilidad en los países desarrollados sólo por los atributos institucionales (39).

No obstante, negar los rasgos institucionales que pudieran reforzar o dañar las posibilidades de la existencia de la poliarquía, podrían haber sido letales. El análisis ha mostrado que la combinación del incremento de la competición política (mediante el crecimiento de la fragmentación y la pérdida de la hegemonía electoral), el Colegio Electoral presidencial y el sistema de representación proporcional fue una mezcla explosiva que ponía en peligro a la misma poliarquía argentina.
(38) Un ejemplo actual puede presentar más claramente el caso. Corrientes, en el noreste argentino, era la única provincia que todavía elegía su gobernador mediante un Colegio Electoral. En 1991 se celebraron las elecciones para la gobernación. El Pacto Autonomista-Liberal, una fuerte alianza local, ganó las elecciones. Obtuvo 13 electores (uno menos de la mayoría). Los peronistas recibieron 9 electores y los radicales, 4. Hubo un pacto antes de las elecciones entre los radicales y los peronistas para votar juntos en el Colegio Electoral al partido más votado de los dos. A pesar de que el PAL fue el claro ganador en las elecciones, hubo una alianza en los votos electorales, 13 para cada bando. Debido a la parálisis electoral, comenzó una serie de complicadas maniobras legales. La Corte de Justicia de Corrientes favoreció al PAL y la Corte Suprema de Justicia apoyó a los peronistas. No se pudo obtener ninguna solución y el gobierno central intervino y designó un gobernador interino ("interventor"). Otra elección para gobernador tuvo lugar en Corrientes en 1992. El PAL ganó las elecciones pero, irónicamente, debido a la distribución de los votos entre las circunscripciones (y la misma desproporcionalidad posible analizada entre los votos populares electorales, obtuvo un elector menos que los peronistas, quienes perdieron la elección en votos populares pero ganaron en el número de electores. Sin embargo, de nuevo, ninguna mayoría absoluta de votos electorales fue obtenida: el PAL obtuvo 11 electores y los peronistas, 12 y los radicales los cuatro restantes y decisivos electores. Otro fatal punto muerto; y volvió a comenzar una serie de batallas políticas y legales. No se logró ninguna solución y tuvo lugar una nueva intervención federal. En este ejemplo, el gobierno nacional resolvió la parálisis interviniendo la provincia. La cuestión fue: ¿quién podría haber resuelto la misma parálisis institucional si hubiera aparecido a nivel nacional en el Colegio Electoral presidencial?
(39) Dahl, R. A Preface to Democratic Theory, Chicago: University of Chicago Press, 1957. 


\section{RESUMEN}

El autor analiza la evolución electoral argentina desde la redemocratización de 1983. En todos los ámbitos territoriales se observa una creciente fragmentación que cuestiona el tradicional bipartidismo entre peronistas y radicales, y afecta a la estabilidad institucional del país - específicamente al colegio electoral- En este contexto, se produce la reforma constitucional de 1994.

\section{ABSTRACT}

The author analyzes the Argentinian electoral evolution from the 1983 redemocratization. There is a growing fragmentation in all territorial frameworks which questions the traditional bipartidism among Peronists and Radicals, and which affect the institutional stability of this country - specifically the electoral college. In this context, the 1994 constitutional reform is approved.
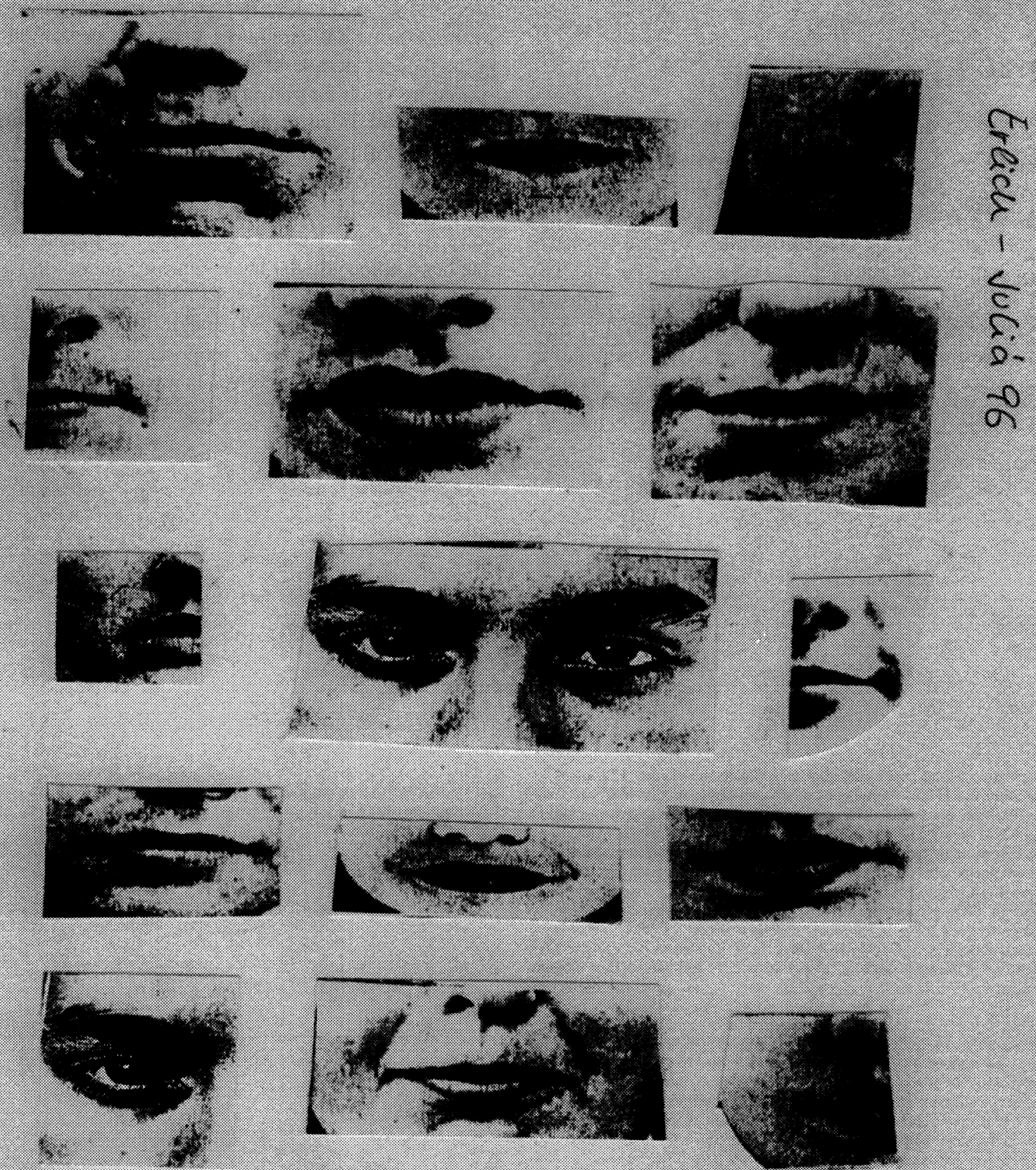